\title{
The Risk Behaviour of People Living With Hiv/Aids
}

\author{
${ }^{1}$ Thokala Sivaiah, ${ }^{2}$ Gaddam Vijayasaradhi \\ 1. Associate Professor, Dept of Community medicine, Guntur medical college, Guntur-522004 \\ 2. Associate Professor, Dept of General surgery, Guntur medical college, Guntur - 522004
}

\begin{abstract}
Background: As HIV is the world's infectious killer and the Guntur District belongs to Andhra Pradesh, India was categorized as "A" basing on the high antenatal HIV prevalence for the last two years as studied by NACO (National AIDS Control Organization), India, has to be given priority to study regarding the risk behaviour of HIV positives.

Objectives: 1. To know the risk behaviour towards transmission and spread of HIV among the positives attending Government General Hospital, Guntur. 2. To identify the HIV and health status of study subjects. Study Design: It is a cross-sectional study.

Study Area: STD OP of Government General Hospital Guntur, Andhra Pradesh.

Study subjects: HIV positive persons attending STD O.P of Government General Hospital, Guntur, Andhra Pradesh.

Sample size: 200. Study

Period: 01-01-2015 to 31-06-2015.

Results: In the study group about $61 \%$ are males \& $39 \%$ are females and are all heterosexuals. Maximum about $88 \%$ of study group belongs to 15-44 years and 33\% belongs to15-29 years of age group with the mean $32 \& M \pm 2 S E=30.16-33.34$ at $95 \%$ CI. And among the total study subjects about $72 \%$ had risk factors towards transmission \& spread of HIV and $28 \%$ have no risk factor which shows that they acquired infection from their life partner only. And among the 72\%, who had risk factors, maximum about $81 \%$ have more than two sexual partners other than spouse and $68 \%$ of them revealed that just because of having interest on sex they had extra marital sexual life. About 46\% had previous h/o S.T.D and 57\% had habit of Alcohol intake. And 46\% of spouse of the study subjects were found to be HIV positive and out of them $18 \%$ had health problems.
\end{abstract}

Keywords: PLWHA (People living with HIV/AIDS), Risk behaviour, S.T.D, Spouse, Guntur

\section{Introduction}

Ever since its recognition in 1981, HIV/AIDS continues to ravage all the continents of the world. A retro virus called Human Immunodeficiency Virus (HIV) is the most significant emerging infectious pathogen of $20^{\text {th }}$ century ${ }^{(1)}$. HIV infection leading to Acquired Immunodeficiency Syndrome (AIDS) is probably the most compelling issue to address for its economic, cultural and social impact in the population worldwide. AIDS sometimes called "Slim disease" has evolved from a mysterious illness to a modern global pandemic which has infected tens of millions in less than 20 years affecting both industrialized and developing countries.

AIDS is a fatal illness caused by HIV which breaks down the body`s immune system, leaving the victim vulnerable to a host of life-threatening opportunistic infections, neurological disorders (or) unusual malignancies ${ }^{(2)}$. According to the current estimates from UNAIDS \& WHO, there were approximately 35 million people worldwide living with HIV in 2013. Of these 3.2 million were children ( $<5 y e a r s)$ and an estimated 2.1 million individuals worldwide became newly infected with HIV in 2013. HIV is the world's leading infectious killer. According to WHO an estimated 39 million people have died since its first cases was reported in 1981 and 1.5 million people died of AIDS-related causes in $2013^{(3)}$.

AIDS is affecting mainly the young people in sexually active age group. Majority of the HIV infections $(88.55 \%)$ are in the age group of 15-49 years, out of which $31.8 \%$ are in the age group of 15-29 years. India has 2.4 million HIV positive people out of which $61 \%$ are males, $39 \%$ are females and $3.5 \%$ are children ${ }^{(4)}$. In India the epidemic shifts from the highest risk group(commercial sex workers, homosexual men, drug users) to bridge population (clients of sex workers, STD patients, migrant population, population in conflict areas and partners of drug users) and then to general population. The high prevalence states (Group I) in India where the HIV infection has crossed 5\% mark in high-risk group and 1\% (or) more in antenatal women are Maharashtra, Tamil $\mathrm{Nadu}$, Andhra Pradesh, Manipur and Nagaland. And all the districts in Andhra Pradesh including Guntur were categorized as "A" by NACO (National AIDS Control Organization) basing on the surveillance data (>1\% of Antenatal HIV prevalence for the last 2 years ${ }^{(5)}$.

In India mainly HIV/AIDS is acquired through heterosexual contact (infected man to woman \& infected woman to man). Every single act of unprotected intercourse with an HIV infected person exposes the 
uninfected partner to the risk of infection. The size of the risk is effected by a number of factors including the presence of STD, the type of sexual act, the duration of sexual life, the number of sexual partners, the stage of illness of the infected partner and the virulence of the HIV strain involved etc.

\section{Material \& methodology:}

The study was conducted during the period from 01-01-2015 to 31-06-2015 at STD O.P of Government General Hospital, Guntur. According to hospital census the prevalence of HIV cases attending STD O.P was found to be $35.5 \%$. The sample size was calculated by using the formula $\mathrm{N}=4 \mathrm{PQ} / \mathrm{L}^{2}$ Where $\mathrm{P}=35.5, \mathrm{Q}=100-\mathrm{P}$ i.e. $64.5, \mathrm{~L}=20 \%$ allowable error in $\mathrm{P}$ i.e. 7.1 , so $\mathrm{N}=182$ and assuming there may be $10 \%$ attrition, additional $10 \%$ was taken which was calculated to be 200. And all the HIV positives attending STD O.P during the above period were selected as study subjects in this study. They were interviewed by using a pre-tested pro-forma including information about the risk factors towards transmission \& spread of HIV, duration \& number of partners of extra marital sexual life, practice of condoms, habit of alcoholism, and the HIV status \& health problems of spouse etc.

The collected data was analysed by using appropriate statistical techniques like percentages, proportions and chi-square test with the help of computer software. The observations were discussed in the light of published material of various authors. The conclusions were made on the synthesis of medical, social and statistical angles of the observation with justified differences with the published work of previous authors. The recommendations were made after detailed study of observations.

\section{Results}

\section{History Of Risk Factors Towards Transmission and Spread Of Hiv}

\begin{tabular}{|c|c|c|}
\hline H/o Risk Factors & No & \% \\
\hline Present & 144 & $72 \%$ \\
\hline Absent & 56 & $28 \%$ \\
\hline Total & 200 & $100 \%$ \\
\hline
\end{tabular}

- $\quad$ Among all the study populations about 28\% (56) have no risk factors related to transmission and spread of HIV that mean they acquired infection from their spouse only and $72 \%$ (144) have risk factors.

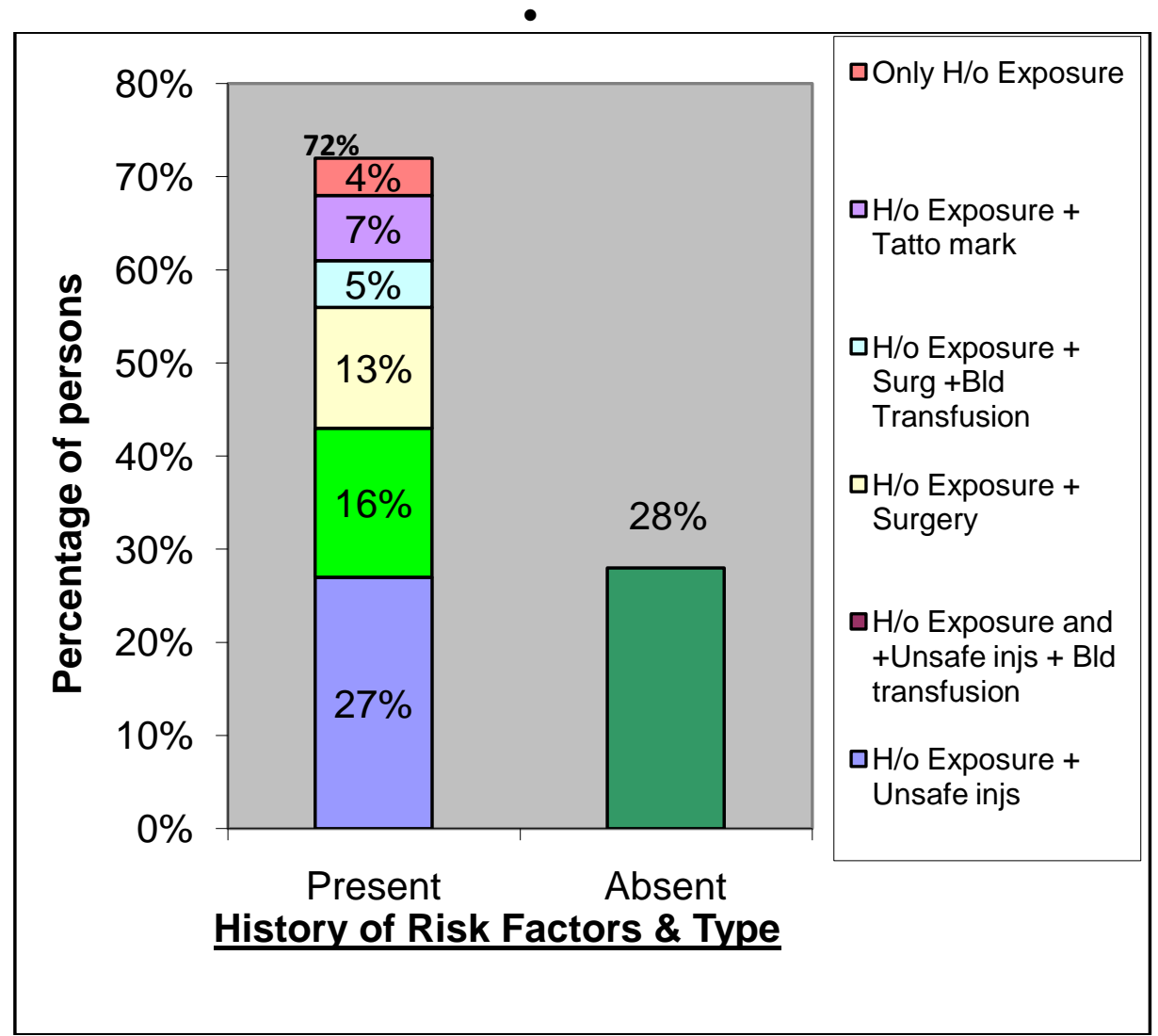

- Out of $72 \%$ (144) who have risk factors almost all the persons have history of exposure (Extramarital sexual life). 
- Among the persons who have history of Exposure 100\% (144), about 27\% have both H/o Exposure + Unsafe injections, 16\% H/o Exposure + Unsafe injections + Blood Transfusion, 13\% have H/o Exposure + Surgery, 5\% have H/o Exposure, Surgery \& Blood Transfusion, 7\% have H/o Exposure + Tattoo mark and 5\% have only $\mathrm{H} / \mathrm{O}$ Exposure.

\section{Number Of Extra Marital Sexual Contacts \& Partners}

\begin{tabular}{|c|c|c|}
\hline Number & $\begin{array}{c}\text { No. of extra Marital Sexual } \\
\text { Contacts }\end{array}$ & $\begin{array}{c}\text { No. of Sexual Partners other } \\
\text { than Spouse }\end{array}$ \\
\hline \hline ONE & - & $8(5 \%)$ \\
\hline \hline TWO & - & $20(14 \%)$ \\
\hline \hline TWO & $148(100 \%)$ & $120(81 \%)$ \\
\hline \hline TOTAL & $148(100 \%)$ & $148(100 \%)$ \\
\hline
\end{tabular}

- Almost all the patients had history of more than two times of Extra Marital Sexual contacts.

- About $81 \%$ of study group had more than two extra marital sexual partners.

\section{Reason For High Risk Sexual Behaviour}

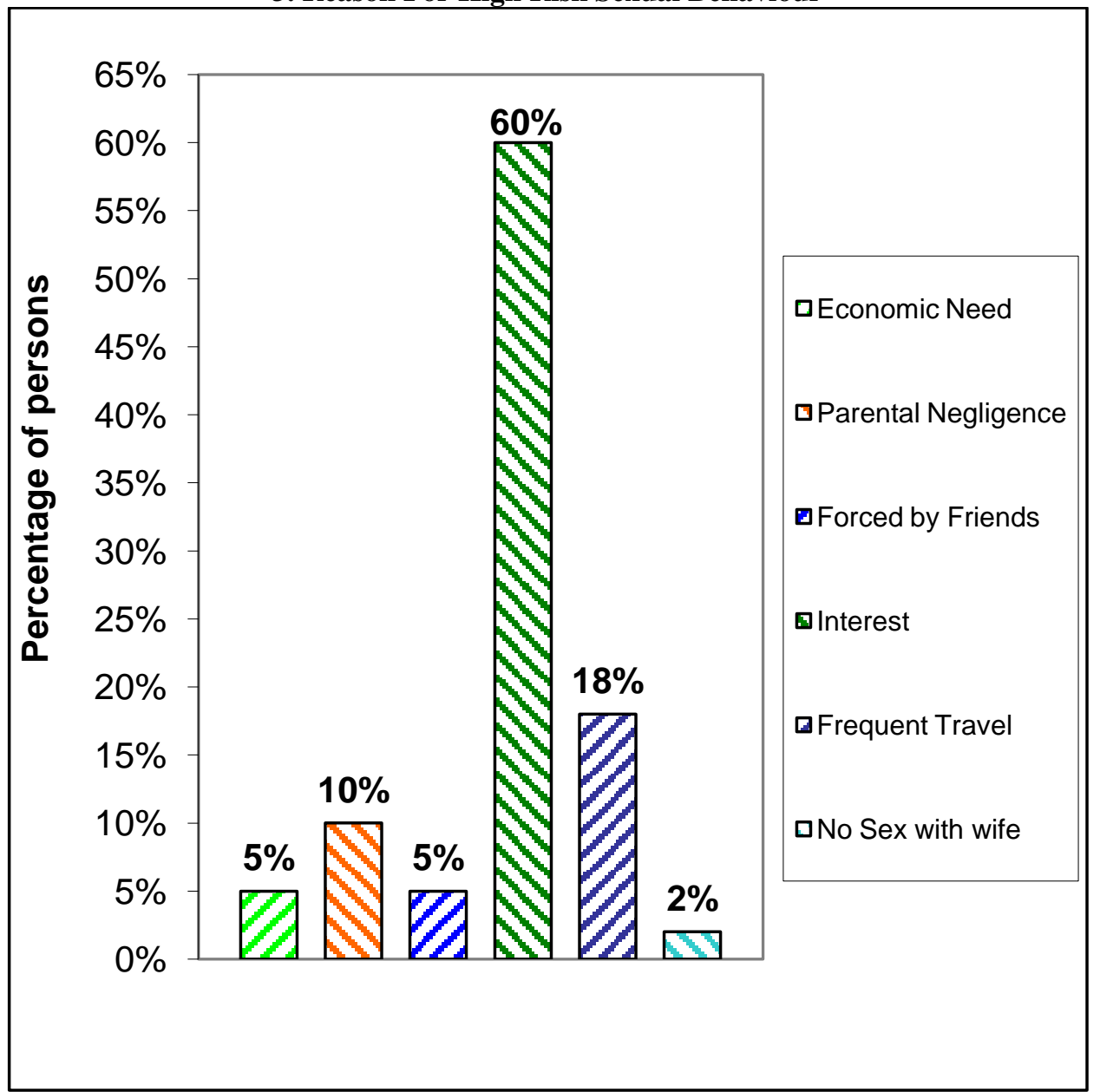

- Maximum $68 \%$ of study group are Habituated to High Risk Sexual Behaviour just because of Interest on sex followed by $18 \%$ frequent travel, $10 \%$ parental negligence, $5 \%$ Economic needs, $5 \%$ Forced by friends and $2 \%$ No sexual life with wife.

4. PREVIOUS HISTORY OF S.T.D.

\begin{tabular}{|c|c|c|c|}
\hline Previous H/o STD & Male & Female & Total \\
\hline \hline Yes & 48 & 44 & $92(46 \%)$ \\
\hline \hline No & 74 & 34 & $108(54 \%)$ \\
\hline \hline Total & 122 & 78 & $200(100 \%)$ \\
\hline
\end{tabular}

$\chi 2=5.578, \mathrm{Df}=1, \mathrm{P}<0.05$ 


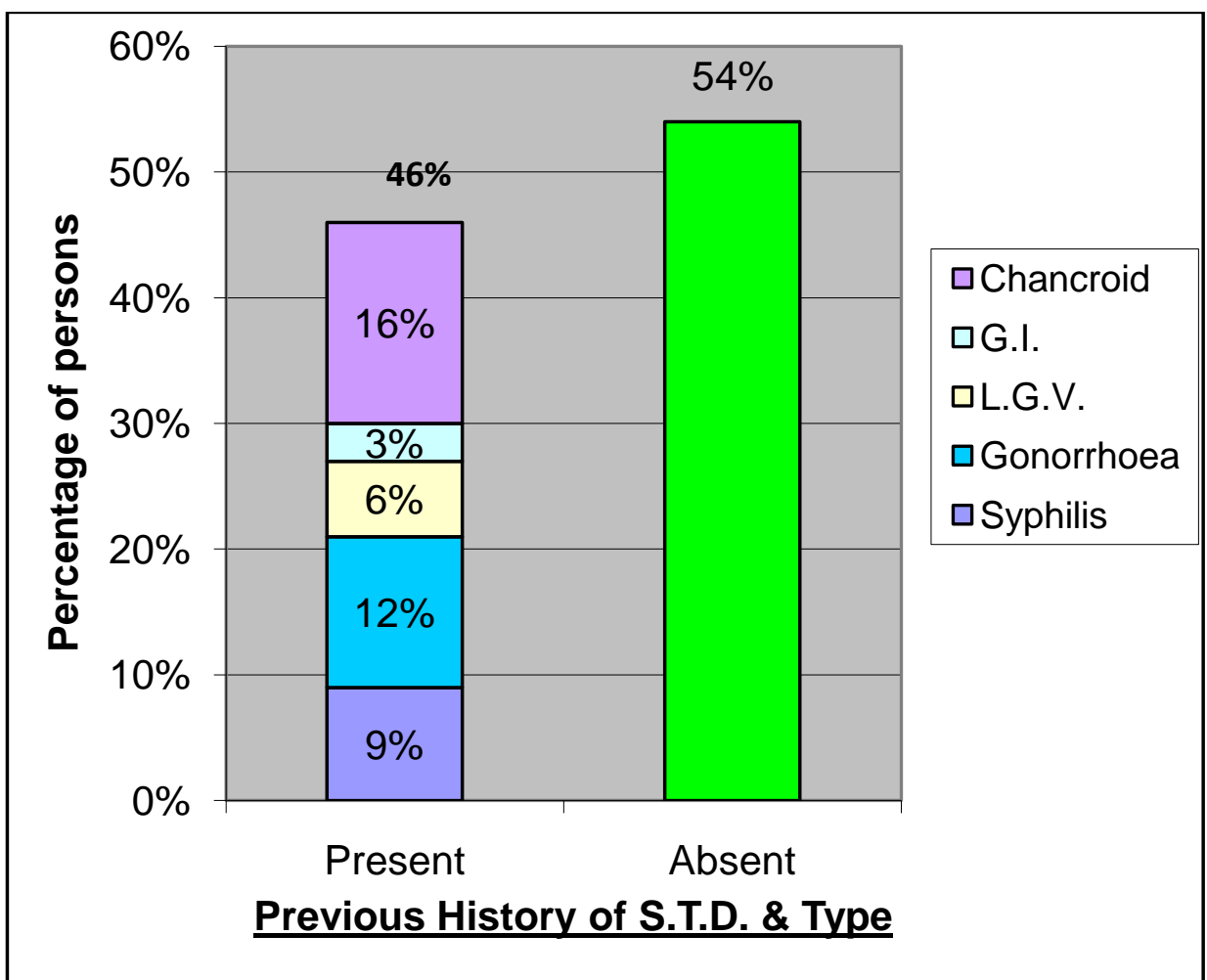

- About $46 \%$ of study group suffered from STD previously and among these, females were more in number when compared to males. And related to distribution of STDs it was observed that about $16 \%$ of patients were suffered from Chancroid, followed by $12 \%$ Gonorrhea, 9\%Syphilis,6\%Lymphogranuloma venereum\& $3 \%$ Granuloma inguinale.

\section{HIV STATUS OF SPOUSE}

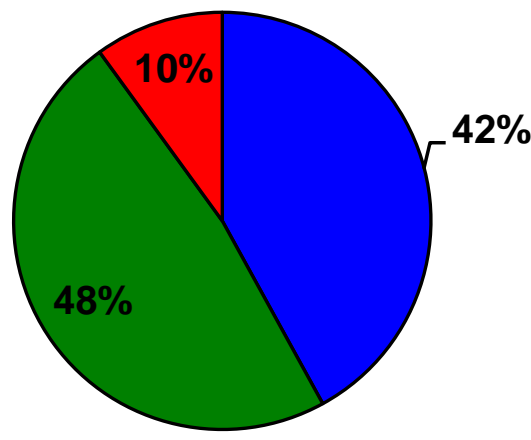

口Positive

$\square$ Negative

$\square$ Not Tested

- Among the entire study group about $92 \%$ (184) have spouse.

- And among the persons who have spouse about $42 \%$ (78) were found to be HIV positive and $48 \%$ (88) were negative and $10 \%$ were not tested.

- With reference to health status of the spouse of the study subjects, about $18 \%$ had health problems at the time of study.

- And about $39 \%$ of the study subjects practicing safe sexual practices (condom usage) with the partner.

\section{Discussion}

Focusing on HIV transmission risk behaviour among HIV positive individuals is a public health priority, especially as infected persons live longer because of improved medical treatment and long incubation period. And the availability of information pertaining to sexual behaviour of risk groups related to HIV is also very less to move further to reduce the prevalence of HIV/AIDS. 
In our study $61 \%$ were males and $39 \%$ were females which correlates with the figures of Anjum Parvej et al study $\left(65.4 \%\right.$ males \& $34.6 \%$ females ${ }^{(6)}$,Kumar A et al study $\left(64.7 \%\right.$ males \& $35.3 \%$ females) ${ }^{(7)}$ and Priyanka et al study $(61.2 \%$ males \& $38.8 \%$ females $){ }^{(8)}$. Among the entire study group about $28 \%(56)$ of patients (study subjects) have no risk factors related to transmission of HIV. That means they acquired infection from their spouse only and $72 \%$ ( 144) have risk factors towards transmission and spread of HIV. Out of these $72 \%$ who had risk factors almost all the persons have History of Exposure. And among these persons who have History of Exposure, 27\% have both History of Exposure \& Unsafe injections, 16\% have H/o Exposure \& Unsafe injections and Blood Transfusion, 13\% have H/o Exposure and Surgery, 5\% have H/o Exposure, Surgery and Blood Transfusion, $7 \%$ have H/o Exposure \& Tattoo mark and about 4\% have only H/o Exposure. By observing the risk factors it is understood that about $68 \%$ of study group have more than one risk factor towards transmission \& spread of HIV/AIDS.100\% of our study population is heterosexuals and the predominant mode of transmission of HIV here is also heterosexual route. We could find the similar observation in Priyanka et al study in panjab ${ }^{(8)}$, Kumar A et al study in Karnataka ${ }^{(7)}$ and Anjum Parvej et al study conducted in north india ${ }^{(6)}$.

Regarding the period of extra marital sexual life, about $66 \%$ of study group had more than 5 years, $28 \%$ between $2-5$ years, $11 \%$ between $1-2$ years and $5 \%$ less than one year of extra marital sexual life. Here also the rate of infectivity is directly proportional to the duration of extra marital sexual life. And almost all the patients $(72 \%)(144)$ of study group had history of more than two times of extra marital sexual contacts. About $80 \%$ of this group had more than two extra marital sexual partners which is closer to the study findings of Kumar A et al (87\%) ${ }^{(7)}$ and Jindal A et al study in Amritsar, Punjab (90\%) ${ }^{(9)}$. And $57.17 \%$ noted in B E Thomas et al study in Chennai in $2009^{(10)}$ and $38 \%$ was noted in Priyanka et al study ${ }^{(8)}$. In an U.S.A study conducted by Weinhardt L S et al nearly $25 \%$ of women \& heterosexual men and $59 \%$ of MSM (Men sex with Men)of HIV positive study subjects had multiple sexual partners ${ }^{(19)}$.So we understood that if the contacts \& partners are more, the rate of infectivity is also more.

With reference to the reason for this risk behaviour towards transmission \& spread of HIV, about $68 \%$ of this study group who had risk behaviour revealed that just because of having Interest on sex they adopted this behaviour, followed by $18 \%$ because of frequent travel (staying away from home temporarily), $10 \%$ because of parental negligence, $5 \%$ because of economic needs, $5 \%$ because of forced by friends and $2 \%$ because of not having sexual life with wife they had this extra marital sexual life. Interestingly about $70.5 \%$ of study population of B.E Thomas et al study said that they had this extra marital sexual behaviour because of curiosity on sex ${ }^{(10)}$ which is nearer to our study figure. As the interest towards sex is the main reason for this high risk sexual behaviour, health education has to be focused to create awareness among the youth intended to adoption of healthy sexual behaviour.

In our study about $46 \%$ of the total study group was suffered from STD previously and $54 \%$ did not suffer from STD. The difference between both the male and female study subjects who had and who did not have the previous H/o STD is statistically also significant $(\mathrm{p}<0.05)$ as the past history of STD is more among females observed in this study. As we know that the presence of STD will favour the transmission of HIV easy and fast.Regarding the type of STD from which they suffered previously it was observed that maximum about $35 \%$ of patients suffered with Chancroid , followed by $24 \%$ Gonorrhoea, $20 \%$ Syphilis, $14 \%$ Lymphogranuloma venereum (LGV) and 5\% Granuloma Inguinale (G.I) respectively. In the study group the presence of ulcerative lesions were more in number which might have impact on the transmission of HIV.

Only about $39 \%$ of our study subjects are practicing condoms after knowing their HIV status which is a welcoming feature in this study and is correlating with the findings (39\%) Avina Sarna et al study ${ }^{(11)}$, Allen S, Serafilira A et al study ${ }^{(12)}$, Yand F, WuZ, Xuc et al study ${ }^{(13)}$. And $(10 \%)$ in Neube et al study in Ghana in the year $2012^{(14)}$. And $0 \%$ usage of condoms is observed in Indian male prisoners as observed by Kate Dalon et al 1n $2010^{(15)}$, followed by $28 \%$ in Manipur \& $40 \%$ in Nagaland among IUDs (Injecting drug users) as per Ritu kumar Misra et al study ${ }^{(16)}$. 46\% usage in Nicola man et al study in Papua, New guinea ${ }^{(17)}, 70 \%$ less likely to use condoms among HIV positive FSWs (female sex workers) in the study of Jadav A et al ${ }^{(18)}$ and $81 \%$ of usage among women \& $84.4 \%$ of usage among MSM and $87 \%$ of usage of condoms among Heterosexual men of HIV positive study subjects in 4 cities USA was observed according to Weinhardt L S et al study ${ }^{(19)}$.

And among all the males (122) about 57\% have habit of Alcohol and 66\% have habit of smoking. Similar findings were observed related to Alcohol in the study of Dr.Chandrakanth et al in Newdelhi and an U.S.A study conducted by Susan Allen et al ${ }^{(20)}$. And we know that the habit of Alcohol is indirectly contributes the high risk sexual behaviour. Among the entire study group about $92 \%$ (184) have spouse. Among the persons who have spouse, about $42 \%(78)$ were found to be HIV positives and 48\%(88) were negatives which is closer to the finding of Jayant D Despande et al study i.e. 37.6\% of spouse of study subjects were found to be positive (21). The above observation shows that nearly about half of the spouse of the study population has HIV infection and among these half of the spouse acquired infection is just because of her/his life partner only.

And among all the spouse of the study subjects about $18 \%$ had health problems. 


\section{Recommendations}

- The aim of sex education, education about HIV/AIDS prevention is to help the person understand, accept and cope up with the diagnosis and prevent serious reactions such as suicide (or) long-term intractable depressions. This education should be continuous and ongoing process.

- As the literacy is the gateway of getting awareness and our study result shows the importance of improvement of literacy to control the spread and prolong the healthy life to PLWHA, the literacy status of the population \& patients also should be improved.

- Since HIV/AIDS is now common in women of child bearing age, the incident of HIV/AIDS is on the rise in children also. So to prevent parent to child transmission it is necessary to educate mothers and adolescent females regarding benefits of antenatal care and importance of PPTCT (Prevention of Parent to Child Transmission) with making HIV screening is mandatory in antenatal clinics to prevent $100 \%$ child transmission.

- As the HIV seropositivity is more in 20-40 years age group which is sexually \& economically productive age group in the family \& country, the youth should be targeted \& sensitized with health education regarding safe sexual practices including use of condoms, avoidance of extra marital sex by means of conducting strengthened awareness and screening campaigns regarding HIV/AIDS with I.E.C (Information, Education and Communication) intervention strategies involving health care staff, volunteers, youth clubs, NGOs, village level workers, opinion leaders and adequate funding etc.

- Strengthening of counselling process is an important aspect of control and prevention of HIV/AIDS because counselling improves the health status of the study subjects by means of improving hygienic practices, taking nutritious diet, adoption of safe sexual practices, abstain from bad habits like smoking \& alcohol, relieving from false beliefs, prevention of suicidal tendencies and keeping the housing environment healthy etc.

\section{References}

[1]. Lederburg J, Slope RE, Oake SC; Eds, Emerging infections; Microbial Threat to Health in the United States, Washington DC; National Academy of Sciences, 1992

[2]. WHO (1986), Techn, Rep. Ser. 736.

[3]. Global statistics- AIDS.gov; Information from WHO, UNAIDS and the Kaiser family Foundation's Global Health policy Division, Nov13, 2014.

[4]. World Aids Day 2013-HIV and AIDS in India, Nirmalya Dutta, Nov 29, 2013.

[5]. HIV/AIDS situation and response in Guntur District; Epidemiological appraisal using data triangulation by Indian Institute of Public Health, Hyderabad. July 2010. Collaborators; DAPCU, Guntur, APSACS, Hyderabad. NACO, New Delhi.

[6]. Clinico - epidemiological profile of HIV patients attending ART centre at a tertiary care centre of North India. - by Anjum Parvez et al; JIACM ( Journal of Indian academy of Clinical Medicine), vol 15, no1,jan-mar 2014.

[7]. Profiles of clients tested HIV positive in VCTC of a district hospital, Udupi, South Karnataka- Indian Journal of Community Medicine 2008;33(3):156-9.

[8]. Risk profiles of HIV positive persons attending integrated counselling and testing centre of a tertiary care hospital, Amritsar. Priyanka et al; JRMDS ; vol 2/issue 2/April-June 2014.

[9]. Trend of HIV infection in police personnel attending VCTC of a tertiary care hospital - Jindal N, Arora U, Indian Journal of Community medicine 2007;32(3),201 - 2 .

[10]. Gender differences in sexual behaviour among people living with HIV in Chennai, India. - B E Thomas et al, - Indian Journal of Medical Research 129, June 2009, PP690 - 694.

[11]. Avina sarana et al, "Effectiveness of community based positive prevention intervention for people living with HIV who are not receiving ART: A prospective cohort study - Global health science practical , March1,2013 vol 1, NO.1 P - 52-67 Doi ; 10 . 9745/GHSP-D -12-00023

[12]. Allen S, Serufilira A et al, "Confidential HIV testing and condom promotion in Africa. Impact on HIV and Gonorrhoea rates. JAMA 1992; 268:3338-43 DOI; 10.1001/JAMA 268, 23, 3338PMID; 1453526

[13]. Yand F, WuZ, Xuc et al, (Acceptability and feasibility of condom use among families with human immunodeficiency virus infection in rural area of China). Zhangua iu Xing Bing Xue Za Zhi; 2001: 22:330-3 pmid:1176968.

[14]. Sexual risk behaviour among HIV positive persons in Kumasi, Ghana. - NM Neube et al; Ghana Medical Journal, March 2012; 46 (1) $27-33$.

[15]. Indian prisoners: Risk behaviour prevalence, prevention and treatment - Kate Dalon et al. IJMR Dec 2010, 132 (6), 696-700.

[16]. High risk behaviour of male injecting drug users and associated non condom use with regular female sexual partners, North East India. - Rithu Kumar Misra et al. - Harm Reduction Journal 2014, Feb 13,11:5.

[17]. Sexual risk behaviour, Marriage and ART: A study of HIV positive people in Papua, New Guinea. - Wing Young Nicola man. Aids Research and Therapy 2013, 10:17.

[18]. Risk behaviours among HIV positive female sex workers in Northern Karnataka, India, - Jadav A et al - Aids Research and Treatment, v01 2013,Article ID 878151,7 pages.

[19]. Weinhardt L S , Kelly JA , Brondino MJ et al - "HIV transmission risk behaviour among men and women living with HIV in 4 cities in the United States. - Journal of Acquired Immune Deficiency Syndrome 2004;36: 1057-66

[20]. Sexual behaviour of HIV discordant couples after HIV counselling and testing AIDS 2003,17:733-740 ; LIPPINCOTT Williams \& Wilkins - conducted by Susan Allen et al

[21]. Clinico-Epidemiological profile of HIV patients attending ART centre in rural western Maharashtra, India. - Jayanth D Desponde et al, South East Asia Journal of Public Health 2012, 2 (2), 16-21. 